\title{
Strategies for managing unsafe precepted nursing students: A nursing faculty perspective
}

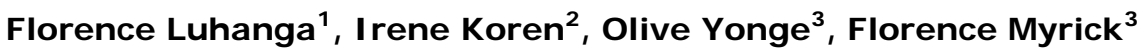 \\ 1. Faculty of Nursing, University of Regina, Regina, Canada. 2. School of Nursing, Laurentian University, Sudbury, Canada. \\ 3. Faculty of Nursing, University of Alberta, Edmonton, Canada.
}

Correspondence: Florence L. Luhanga. Address: Faculty of Nursing, Research and Innovation Centre, University of Regina, Regina, Saskatchewan, Canada. Email: florence.luhanga@uregina.ca

Received: December 14, 2013

Accepted: February 25, $2014 \quad$ Online Published: March 24, 2014

DOI : $10.5430 /$ jnep.v4n5p116

URL: http://dx.doi.org/10.5430/jnep.v4n5p116

\section{Abstract}

Background: To ensure safe practice, educational programs are regulated by academic and legal guidelines to prepare graduates who are at the very least competent novice nurses. The preceptorship model is widely used in Canadian nursing programs as an effective strategy in the clinical education of students who are preparing to transition to professional practice. For nursing faculty who are responsible for the final determination of student success in a clinical rotation, a challenge arises when a preceptor identifies a student as unsafe in practice.

Method: The authors conducted a grounded theory study to explore the process that nursing faculty use when working with students whose preceptors have reported them as unsafe in the final year of their undergraduate program. Data were collected primarily through individual semi-structured interviews with six nursing faculty and the constant comparative method was used to analyze the data.

Results: 'Promoting student success' emerged as the core variable or main concern, with six inherent major categories: (a) recognizing red flags of unsafe practice, (b) strategies for managing students with unsafe practice, (c) evaluation strategies for success, (d) decision to fail a student, (e) guidance and support for student and preceptor, and (f) guidance and support for faculty. In this article the authors focus on three of these categories: (a) strategies for managing students with unsafe practice, (b) evaluation strategies for success, and (c) decision to fail a student.

Conclusion: The findings have implications for ongoing support for faculty involved in the preceptorship program. Administrators in nursing education programs need to reflect on these findings and support faculty in preparing for and engaging in their role in the preceptorship experience.

\section{Key words}

Grounded theory, Preceptorship, Faculty, Unsafe nursing student, Strategies

\section{Introduction}

Patient safety is an essential component of quality health care and a matter of major concern to the nursing profession. To ensure safe practice, educational programs are regulated stringently by academic and legal guidelines to prepare graduates who are competent novice nurses ${ }^{[1,2]}$. The preceptorship model is widely used in undergraduate nursing education programs as an effective teaching-learning strategy for the transition of nursing students to professional practice ${ }^{[3-5]}$. This 116 
model pairs a senior nursing student with an experienced registered nurse ([RN] the preceptor) employed by a health care agency and a faculty member for the duration of a clinical experience ${ }^{[6,7]}$. The student, preceptor, and faculty member together form a teaching-learning triad in which each member plays a vital role in the success of the preceptorship experience and in the preparation of the nursing student as a safe and competent beginning practitioner ${ }^{[4]}$. The preceptor is responsible for the day-to-day teaching and supervision of the student, while the faculty member acts as the link between the educational institution and the practice setting and acts as resource for the teaching and learning process in this triad ${ }^{[4]}$. In their role, the faculty respond to concerns and support both the preceptors and students alike, guide the preceptor in the evaluation of the students' clinical performance and is ultimately responsible for assigning the final grade ${ }^{[3,4]}$.

To date, however, minimal research has been carried out to explore the process of working with students who demonstrate unsafe behaviors during preceptorship, particularly from the perspective of faculty members. To that end, we conducted a grounded theory study to explore the process that faculty use to work with students whose preceptors have assessed them as unsafe in the final year of their undergraduate program. Part of the findings related to the three categories that emerged from the data will be discussed in the paper. These include: (a) strategies for managing students with unsafe practice, (b) evaluation strategies for success, and (c) decision to fail a student. The other findings have been reported elsewhere.

\section{Literature review}

Invariably, it is challenging to be a preceptor and to observe students who are displaying unsafe nursing behaviors, particularly when they are in their final year ${ }^{[8]}$. Given that the preceptors' first responsibility is to safe patient care, with their preceptor role secondary, their interpretation of what unsafe means can sometimes range from intuitive to a direct observation of student behavior that requires intervention to maintain patient safety.

In preceptorship, clinical evaluation of students is particularly challenging for faculty members owing to the fact that they rarely directly observe or supervise student performance ${ }^{[9]}$. Faculty might therefore find it challenging to determine the appropriate course of action or could even judge the students' performance severely and in turn fail them for actions that the faculty might not even have observed. This lack of direct supervision thus creates a dilemma for faculty. In other words, faculty require a mechanism with which to monitor students’ progress to be able to assign a final fair grade.

Furthermore, evidence has shown that faculty do not always agree on what constitutes unsafe practice ${ }^{[8,10]}$, which can invariably compound the situation if they pass students who have displayed unsafe behaviors or if they have allowed them to start a preceptorship, knowing that the students might not succeed ${ }^{[8,11]}$. Regardless of the educational context, however, the priority is to identify unsafe clinical practice and to intervene as soon as possible ${ }^{[12-14]}$. Thus, there is a need to further explore the issue of management of student unsafe practice in the preceptorship context, particularly from the perspective of faculty, a topic which has rarely been addressed in the literature to date.

For the purpose of this study, unsafe student practice is perceived as being relative to course expectations and ultimately program outcomes. Unsafe practices include a student's act or behavior that reflects a lack of knowledge, skills, or clinical judgment, or any unprofessional or unethical conduct that threatens or has the potential to threaten the physical, emotional, mental, or environmental safety of the client, self, or other health care personnel ${ }^{[13-15]}$.

\section{Methods}

\subsection{Design}

Given the lack of research that has explored faculty perspectives on students who demonstrate unsafe behaviors during the preceptorship, a grounded theory as explicated by Glaser and Strauss ${ }^{[16]}$ was used as the methodology for this study. This method was considered the most suitable because it allowed the researchers to identify the psychosocial process in which faculty engage when they deal with students whose preceptors have reported them as unsafe, and to directly address what 
is happening in that process, rather than what should be happening. The research questions that guided this study were as follows: (a) What are the perceptions of faculty regarding a final-year nursing student who displays unsafe practice in the preceptorship experience? (b) How do faculty contend with the evaluation and follow-up of such a student? and (c)What challenges do faculty face in managing a student who displays unsafe practice in the final preceptorship experience?

\subsection{Sample and setting}

The sample comprised six faculty members involved in the final year of a baccalaureate nursing program in a mid-sized university and three affiliated colleges located in eastern Canada. All participants were female. Five were prepared at the master's level, and one had earned a doctorate. They had from 22 to 40 years of nursing practice experience and $11 / 2(n=1)$ years to 25 years of experience teaching in nursing education. The main criteria for inclusion were the ability to speak English and involvement in a structured final-year practice-based course using a preceptorship model.

\subsection{Data collection}

For this study we collected data mainly through individual semistructured interviews (of between 60 and 90 minutes) with six nursing faculty. In addition, we reviewed relevant documents, including a preceptorship resource manual and course outlines, to augment the data. Between June 2010 and September 2010 a graduate research assistant conducted the interviews. Because we collected the data from a geographically dispersed sample, the research assistant interviewed three participants by phone and conducted three face-to-face interviews. Questions derived from the literature guided the interviews; they evolved according to the participants' responses and the emerging categories/themes. The open-ended questions included the following:

1) What is your experience like working in a preceptorship model of clinical teaching?

2) What specific student behaviors do you regard as unsafe in the clinical setting?

3) How do you deal with a student who has been assessed as unsafe by a preceptor?

4) What strategies or guidelines do you use to evaluate a student whom a preceptor has assessed as unsafe?

These open ended questions were only used as a guide to facilitate discussion based on participants' experience rather than following the real or perceived direction of the interviewer. As such, participants were encouraged to explore the topics that they considered important to the extent that they were comfortable.

Once we had collected and analyzed the initial data, we based further decisions about the participants, sample size, and the type of data to be collected on the emergent categories ${ }^{[17]}$. The data collection and analysis continued until we achieved

theoretical saturation ${ }^{[17,18]}$. We audiotaped the interviews with the participants' permission after we had obtained demographic data from each participant. We also maintained a journal throughout the study.

\subsection{Data analysis}

We analyzed the data using constant comparative analysis ${ }^{[16,17]}$. The first and second author independently analyzed all of the data and met several times to reach a consensus on the coding process and the emerging themes. The data analysis occurred simultaneously with the data collection. Inherent to that analysis were two levels of coding: substantive and theoretical. Substantive coding involved two levels: open coding and selective coding ${ }^{[18,19]}$.

The first level of analysis, open coding, involved reading the data several times; key words or phrases, patterns, or events were identified and carefully compared with subsequent transcripts where similar words, phrases, ideas, or associations occurred ${ }^{[17-19]}$. This process of open coding resulted in approximately 150 substantive codes or categories and their characteristics from indicators such as actual events, definitions, and meanings derived directly from the research data ${ }^{[19]}$. We identified two types of substantive codes or categories in this study. Those derived directly from the participants' own words or language we referred to as in vivo codes ${ }^{[19]}$. Examples in this study were "student's success," "facilitating", 
“counseling”, “documentation”, “learning contract”, “coaching”, “supporting”, working with”, and "being present”. We constructed implied codes based on concepts derived from the data, such as "being involved and available", "facilitating learning”, "faculty perceived role”, "facilitate communication”, "self-reflection”, “opportunity for remediation”, "strategies for success", "evaluation strategies for success", "guidance and support", and "assigning a failing grade" $[17,19,20]$.

In the second-level coding analysis or theoretical coding we ordered the data and determined the interrelations of the substantive categories. Consequently, we collapsed the substantive codes that we had developed in open coding into categories or higher-level concepts, including strategies for managing unsafe practice. In the next level of analysis was, or selective coding, the core variable for the study emerged from the process of reduction and comparison; which was labeled "Facilitating student success". Once we had identified the core variable, we concentrated on modifying the categories and integrating the theory with the categories and subcategories ${ }^{[17,21]}$.

Throughout the analytic process, we wrote memos to show the theorizing write-up of the codes and their relationships ${ }^{[22,17-19]}$. These memos contained, for example, our impressions of the participants' experiences and their reactions. In addition, we used the memos to systematically question some of our preexisting ideas in relation to what the participants had reported in the interviews. During the memo writing we were guided by a number of questions that, while allowing the true emergence of the categories and their properties, helped to keep us from becoming lost in experiencing the data ${ }^{[17-19]}$. These questions included the following: What relationship does one code have with another? Are they separate codes, or is one code a property or a phase in another? Was one event the cause or the consequence of another? What were the conditions that influenced the codes? ${ }^{[23]}$ What does this segment of data tell me about the theoretical properties of this category ${ }^{[18]}$ ? For example, what was the relationship between the decision to fail and the faculty member's previous experience or support from the educational institution? How did the faculty determine which student behaviors, actions, or attitudes would result in clinical failure?

\subsection{Ethical consideration}

We attained approval to conduct the study from the university research ethics review board. Informed consent was obtained from each participant. To ensure confidentiality, participant names were deleted from the audio tape recordings, written transcripts or field note and replaced with code numbers.

\subsection{Rigor}

To maintain rigor, we used four criteria: credibility, fittingness (also termed transferability), auditability, and confirmability ${ }^{[20,24,25]}$. We achieved credibility through peer debriefing ${ }^{[20,26]}$, and we determined the fittingness of the findings by asking independent experts to read and comment on them. Excerpts from the participants' transcripts are presented in the findings to facilitate the auditability of the data analysis and findings ${ }^{[20,24,26]}$. As well, we kept a comprehensive audit trail and recorded our theoretical memos to facilitate auditability ${ }^{[24,27]}$. We met the criterion of confirmability once we had established credibility, fittingness, and auditability ${ }^{[28]}$.

\section{Results}

"Facilitating student success" emerged as the primary concern, or core variable, for the faculty: "I think the goal is to always try and provide whatever we can to ensure that the student is successful.” Six major categories emerged from the data: (a) recognizing red flags of unsafe practice, (b) strategies for managing unsafe practice, (c) evaluation strategies for success, (d) decision to fail a student, (e) support and guidance for student and preceptor, and (f) support and guidance for faculty. The first three categories involved ensuring that proper evaluation occurs before a determination of failure is made. Category (d) is making that decision to fail, and categories (e) and (f) involved supporting the needs of all involved in the 
triad. In this article we will focus on three categories including: strategies for managing students with unsafe practice, evaluation strategies for success, and decision to fail a student.

\subsection{Strategies for managing students with unsafe behavior}

The participants discussed a range of strategies that they used to respond to students whose preceptors had reported as being unsafe: (a) communicating and clarifying the issue with both the student and preceptor, (b) encouraging self-reflection, (c) encouraging the preceptor to document the specific behaviors or attitudes, (d) developing a learning contract or plan of action for success, and (e) providing remedial intervention.

All of the participants emphasized the importance of prompt faculty communication of concerns to the student. Once the preceptor reported unsafe student practice to them, the faculty then communicated the concern directly to the student. At that point they would try to ascertain whether the student was aware of the problem, and both the student and faculty would work together to identify the source of or contributing factors to the unsafe behavior in clinical practice. One faculty explained, "What I have done in the past is always talk to that student to ask them about how they saw themselves behave, and did they want to do some reflection and think about what happened?"

Other participants reported that they would encourage the student to self-assess or reflect on the situation. Thereafter, they would give the student an opportunity to respond and, if possible, indicate how the student plans to improve his/her performance. Some participants emphasized the importance of acquiring "both sides of the story." In addition, to clarify the situation, the faculty met with both the preceptor and the student to gain a better understanding of the unsafe practice concern. One participant noted:

I try as much as possible to have an understanding of why the preceptor considers the student unsafe. ...I meet with the student and preceptor together and try to [determine] what specifically is the student not safe with or why do you deem the student unsafe? ... Which course outcomes on the clinical evaluation tool are not being met? ...Just saying the student is unsafe isn't really helpful...so try to clarify and relate this [unsafe practice] with the course outcomes.

All of the participants initiated a learning contract once they had confirmed evidence of unsafe practice; its purpose was to enable the student to improve and succeed. The following comment illustrates the contract:

A collaborative success plan [learning plan] helps us to identify very clearly what the change in behavior or expectations are for the student and includes a deadline date for reassessment and follow-up, and in the event that the clinical success plan is not effective, ... then there is some risk that the [student] would not be successful in the course.

Another participant explained that "I try to get them [students] to be successful through the learning contract [plan], but if all else fails and they are still not doing well, then they will fail the course.”

The faculty acknowledged the importance of documenting clear, specific examples of concerns or issues, reasons for failure, and any supportive measures that they undertook. They emphasized that both preceptors and faculty alike are responsible for this documentation, but the faculty rely heavily on the preceptors to provide the documented evidence. One participant stated:

I always ask a preceptor to document ..."If you think that the student is unsafe or not meeting the course objectives and expectations, then please document the behavior or what they're doing.” ... I think it is important that we have that documentation that will support whatever grade level is assigned. 
Another faculty described her recent experience with a final-year nursing student who did not meet the performance or course objectives and reported that the preceptor had kept detailed documentation to support her decision to fail the student:

The preceptor had provided some very detailed feedback all the way along and had sort of set up some objectives for behavior change as well, so we were pretty confident based on what we were getting from the preceptor that the information was accurate.

Because a clinical failure results in a course failure for the student, faculty try to give the students every opportunity to improve through remedial experiences: "Sometimes the student has to come back and go into our resource lab, and we may set up some experiences with our lab support person to practice.” Others suggested that the students should be given a chance to repeat the practicum or be granted an extension of the practicum if they are struggling.

\subsection{Evaluation strategies for success}

We asked the participants to describe the strategies that they used to evaluate students whom preceptors had assessed as unsafe and to determine the final clinical grade. Safety is critical. Without exception, all of the participants identified it as the key factor in the final decision to either pass or fail a student. One participant clearly explained: "The key thing is, Is the patient's safety being jeopardized? And if [it] is, you know, that's a big issue so we have to make sure. ... They have to go back and do some more classroom work."

Some of the faculty reported relying on the formal course-evaluation indicators as the basis for their clinical-grading decisions. Other participants indicated the importance of acquiring additional feedback from colleagues, including clinical staff and course professors, and the program learning objectives to verify a student's level of competence and to determine if the unsafe practice was a single incident or a pattern of behavior.

\subsection{Decision to fail}

Although the participants reported that clinical failure is not a common occurrence, they still acknowledged that if a student does not meet the clinical performance objectives by the completion of placement, the student receives a failing grade. All participants emphasized that persistent unsafe behavior following remedial intervention leads to clinical failure and, ultimately, course failure. They acknowledged that the decision to fail a student is a difficult one in that it can be challenging to align preceptors' and faculty’s decisions. One faculty explained:

I find most preceptors, they want the student to be successful as well, to the point that they have a hard time; some of them have a hard time addressing concerns. They come up with excuses on the student's behalf, and I'm sometimes harder on them than the preceptor would be.

Others reported feeling pressured to pass students but justified the decision to fail in terms of their role of gatekeepers to the nursing profession:

Sometimes in the past I have had some kind of pressure to [decide], "Is this really a failure, or can we pass the student," and I stand where, if the preceptor is not happy and very worried and there is documentation and evidence of that kind of behavior, then I take a hard line that "No, the student should not pass," and I think that partly is because I'm a registered nurse with a license, [which] means that I am responsible for the evaluation of students.

\section{Discussion}

The findings from this study revealed that the core variable or main concern for faculty was a process the researchers described as "Facilitating student success," with patient safety used as their benchmark when making a decision to either 
fail or pass the student. Although only a small number of faculty participated in this study, the findings concur with those from previous studies ${ }^{[13,14,29]}$ highlighted in the literature ${ }^{[10,30]}$. These include: a) the need for early identification and management of unsafe clinical practice critical to ensure patient safety; and b) the importance of focusing on increasing the students' chances for success in their learning vis a vis the opportunity to succeed.

To this end, the participants in this study described several strategies they used to work with students who demonstrated unsafe practice in their clinical practicum. These strategies include: first, communicating and clarifying the issue with both the student and preceptor; second, encouraging self-reflection; third, facilitating and guiding the preceptor to document the specific behaviors or attitudes; fourth, developing a learning contract or plan of action for success; and fifth, providing remedial intervention. These findings are consistent with those in the literature ${ }^{[4,14,29,30]}$. The nurse preceptors in Luhanga, Yonge, and Myrick's study explained that once they identify an unsafe practice, they communicate their concern directly to the student and clarify the issue with the student. The preceptors then give the student an opportunity to reflect on the issue and, if possible, to identify the factor(s) that might be contributing to the problem. Myrick and Yonge ${ }^{[4]}$ emphasized the importance of communicating the concern directly to the student and establishing his or her perspective on the behavior or poor performance. Similarly, the participants in the current study reported that when preceptors report students as unsafe, they communicate such concerns initially to the students to determine whether they are aware of the problem and, if possible, to identify the factors that might be contributing to such behavior. Only through self-assessment or reflection can students identify areas in which they need to improve. It is important, therefore, to ensure that students fully understand the issue and to inform them about the potential implications of their behavior or unacceptable performance.

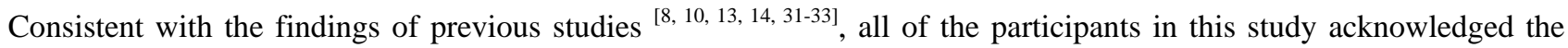
importance of the context and pattern or frequency of the behavior to determine both the seriousness of unsafe practice and the appropriate response to unsafe practice. Tanicala, Scheffer, and Roberts ${ }^{[33]}$, for example, explain that factors such as the clinical environment, the student's year of study, and the timing in the semester can impact the evaluation of clinical behaviors. Killam, Luhanga, and Bakker ${ }^{[10]}$ suggest that factors including the type of event or behavior, the pattern and frequency of the behavior, and the level of risk associated with the student's behavior need to be considered in determining an appropriate response to a student's unsafe behavior.

Another strategy that the faculty in this current study emphasized is documentation. Congruent with the findings from the literature and previous studies ${ }^{[14,31,34]}$, the participants noted that documentation must be factual and nonjudgmental, highlight strengths and areas that require improvement, and include specific examples when appropriate. Duffy and Hardicre ${ }^{[34]}$, for example, stress that "each feedback session should be recorded, with details of the supportive measures taken and the learning opportunities provided to enable students to reach the level of practice required" (para. 2). Other authors asserted that a clear, well-evidenced report not only supports the evaluator's decisions, but also gives students a degree of protection against an unfair decision to fail ${ }^{[12,31]}$.

One faculty member emphasized the importance of communicating to preceptors the importance of documenting specific unsafe events or behavior and explaining that they (preceptors) are not responsible for assigning the final grade. This information is critical as some preceptors are reticent about taking the responsibility for the decision to fail a student. Given the faculty's lack of direct supervision of student performance, they rely heavily on feedback and recommendations from preceptors to assign final grades, thereby further affirming that the role of the faculty member is key to the success of the preceptorship experience ${ }^{[4]}$ and even more when decisions have to be made about students' clinical performance ${ }^{[35]}$.

Another strategy that faculty used in this study to facilitate student success was a learning contract. Participants stressed the importance of a student and preceptor jointly setting up and documenting a detailed action plan or contract to give the student learning opportunities for improvement - in other words, due process. Similarly, many authors recommend the development of a joint learning contract or plan ${ }^{[4,14,30,36]}$ to manage unsatisfactory or unsafe clinical practice. Myrick and Yonge ${ }^{[4]}$ explain that it is important that the faculty member who is responsible for the student be informed and included 
in the development of the learning contract. Teeter ${ }^{[30]}$ recommend that faculty develop and sign a written "contract with the student for success" (p. 92) and that the learning contract be objective, positive, and encouraging and focus on behavior for success rather than failure. It should also include the student's suggestions for the resources needed for improvement.

The faculty in this study further described several remedial interventions they use for students, most of which have been documented in the literature. The types of interventions selected depend on the nature and severity of the unsafe practice. These interventions include, but are not limited to, the provision of additional support strategies such as extra coaching and assistance with clinical preparation, additional skills, laboratory opportunities ${ }^{[14]}$, a change of environment or preceptor $^{[14]}$, and additional or repeat practica ${ }^{[4,8,14,30]}$.

Lastly, all faculty members in this study clearly stated that if the issue of unsafe practice cannot be resolved by the completion of the clinical practicum, then, for the sake of patient safety, the student must receive a failing grade, a view that several authors have supported ${ }^{[4,8,14,30,35,37,38]}$. Although faculty have a responsibility to guide students to succeed in their program, they must also continually weigh the abilities of their students against the potential risk to the patients. Faculty have a duty to ensure that only students with the appropriate knowledge, skills, and values requisite for safe patient cares are admitted to professional practice ${ }^{[37,38]}$, thereby protecting society from unsafe practitioners.

\section{Limitations}

A major limitation of this study is the small sample size. Hence, these findings may not be generalized to the broader community based on this study alone. Secondly the study focused on the experiences of six nursing faculty in one collaborative BScN nursing program in eastern Canada, which also contributes to the limitation of its generalizability to other educational settings and geographical locations.

\section{Conclusion}

The findings from this study reveal that the major concern of faculty is to facilitate student success. To this end they discussed a range of strategies they implemented to respond to students whose preceptors had reported them as being unsafe in the provision of patient care. These strategies included: communicating and clarifying the issue with both the student and the preceptor; encouraging self-reflection; encouraging the preceptor to document specific behaviors or attitudes that reflect unsafe practice; developing a learning contract or plan of action for success; and providing remedial intervention. However, at all times, patient safety was the key hallmark that faculty used when a clinical grade decision was made. The findings of this study can serve to advance the knowledge regarding the preceptorship of senior nursing students by generating strategies that faculty can use to work with nursing students who display unsafe clinical practice. Furthermore, the findings affirm the importance of the faculty role and how it is integral to the success of preceptorship and the decisions that have to be made about students' clinical performance ${ }^{[4,35]}$. Moreover, faculty serves as a major resource to the evaluation process of safe student practice. Administrators in nursing education programs need to reflect on these findings and support faculty in preparing for and engaging in their role in the preceptorship experience. Ultimately resources need to be directed to ensure adequate preparation of faculty advisors and support of the advisors during the preceptorship experience. Also the link between the university and practice areas needs to be fostered to ensure good relations that will enable and support preceptors in their role of assessing nursing student preparedness for transition to professional practice.

\section{I mplications for nursing education}

The findings of this study highlight, to university faculty and administration, program structures and processes that may require adjustments so as to minimize the potential for unsafe practice. These include but are not limited to: (a) 
re-examination of the curriculum to ensure that students are adequately prepared with the required knowledge, skills and competencies prior to engaging in the preceptorship experience; (b) development of strategies and guidelines for dealing with unsafe students; (c) the provision of professional development initiatives for faculty regarding their roles and responsibility as gate keepers to the profession and stake-holders in the patient safety initiatives; and (d) the selecting of suitable students for preceptorship, a process which is critical not only for patient safety but also for student achievement of course objectives, and reduction of the level of burden on both faculty and preceptors.

Nurse educators and administrators are challenged to look within and systematically review how the program structures and processes (such as the curriculum and clinical teaching strategies) may be contributing to students' unsafe practice in their final practicum.

\section{References}

[1] Canadian Nurses Association. Code of ethics for registered nurses. Ottawa: Canadian Nurses Association, 2008.

[2] Johnston EG, Halstead JA. The academic performance of students: legal and ethical issues. In Teaching in Nursing. DA Billings, JA Halstead, eds, 2nd ed. St. Louis, MO: Elsevier Saunders, 2005; 41-66.

[3] Altmann TK. Preceptor selection, orientation, and evaluation in baccalaureate nursing education. Int J Nurs Educ Scholarsh 2006; 3(1): 1-15. http://dx.doi.org/10.2202/1548-923X.1014

[4] Myrick F, Yonge O. Nursing preceptorship: connecting practice and education. Philadelphia, PA: Lippincott Williams \& Wilkins, 2005.

[5] Udlis KA. Preceptorship in undergraduate nursing education. J Nurs Educ. 2008; 47(1): 20-29. PMid:18232611 http://dx.doi.org/10.3928/01484834-20080101-09

[6] Bourbonnais FF, Kerr E. Preceptoring a student in the final clinical placement: reflections from nurses in a Canadian hospital. J Clin Nurs. 2007; 16(8): 1543-9. PMid:17655543 http://dx.doi.org/10.1111/j.1365-2702.2006.01828.x

[7] Mohide EA, Matthew-Maich N. Engaging nursing preceptor-student dyads in an evidenced-based approach to professional practice. Evid Based Nurs. 2007; 10(2): 36-40. PMid:17431963 http://dx.doi.org/10.1136/ebn.10.2.36

[8] Brown Y, Neudorf K, Poitras C, Rodger K. Unsafe student clinical performance calls for a systematic approach. Can Nurse. 2007; 103(3): 29-32. PMid:17410926

[9] Seldomridge LA, Walsh CM. Evaluating student performance in undergraduate preceptorships J Nurs Educ. 2006; 45(5): 169-176. PMid:16722499

[10] Killam L, Luhanga F, Bakker D. Characteristics of unsafe undergraduate nursing students in clinical practice: An integrative literature review. J Nurs Educ. 2011; 50(8): 437-46. PMid:21598859 http://dx.doi.org/10.3928/01484834-20110517-05

[11] Duffy N, Stuart G, Smith S. Assuring the success of part-time faculty. Nurse Educ. 2008; 33(2): 53-4. PMid:18317311 http://dx.doi.org/10.1097/01.NNE.0000299502.09658.97

[12] Boley P, Whitney K. Grade disputes: considerations for nursing faculty. J Nurs Educ. 2003; 42: 198-203. PMid:12769423

[13] Luhanga F, Yonge O, Myrick F. Hallmarks of unsafe practice: what preceptors know. J for Nurses in Prof Dev. 2008; 24(6): 254-264.

[14] Luhanga F, Myrick F, Yonge O. Strategies for precepting the unsafe student. J for Nurses in Prof Dev. 2008; $24(5): 214-219$. PMid:18838899 http://dx.doi.org/10.1097/01.NND.0000320693.08888.30

[15] Scanlan JM, Care WD, Gessler S. Dealing with unsafe students in clinical practice. Nurse Educ. 2001; $26(1): 23-27$. PMid:16372451 http://dx.doi.org/10.1097/00006223-200101000-00013

[16] Glaser BG, Strauss A. The discovery of grounded theory: strategies for qualitative research. New York: Aldine de Gruyter, 1967.

[17] Glaser BG. Theoretical sensitivity. Advances in the methodology of grounded theory. Mill Valley, CA: Sociology Press, 1978.

[18] Holton JA. The coding process and its challenges. Grounded Theory Rev: Int J. 2010; 1(9): 21-40. http://groundedtheoryreview.com/2010/04/02/the-coding-process-and-its-challenges/.

[19] Munhall PL. Nursing research: A qualitative perspective, 5th ed. Sudbury, MA: Jones \& Bartlett Learning, 2012.

[20] Streubert HJ, Carpenter DR. Qualitative research in nursing: advancing the humanistic imperative, 5th ed. Philadelphia, PA: Lippincott, Williams \& Wilkins, 2011.

[21] McCann T, Clark E. Grounded theory in nursing research: part 1. Methodology. Nurse Res. 2003; 11(2): 7-14. PMid:14708425 http://dx.doi.org/10.7748/nr2004.01.11.2.7.c5918

[22] Birks M, Chapman Y, Francis K. Memoing in qualitative research: probing data and processes. J Res Nurs. 2008 ; $13(1)$ : 68-75. http://dx.doi.org/10.1177/1744987107081254 
[23] Munhall PL. Nursing research: a qualitative perspective, 3rd ed. Sudbury, MA: Jones \& Bartlett Learning, 2001.

[24] Cooney A. Rigour and grounded theory. Nurse Res. 2011; 18(4): 17-22. PMid:21853888 http://dx.doi.org/10.7748/nr2011.07.18.4.17.c8631

[25] Guba EG, Lincoln Y. Fourth generation evaluation. Newbury Park, CA: Sage, 1989.

[26] Lobiondo-Wood G, Haber J. Nursing research in Canada: methods and critical appraisal for evidence-based practice, 8th ed. Toronto, ON: Mosby/Evolve, 2013. PMid:24067357

[27] Houghton C, Cassey D, Shaw D, Murphy K. Rigour in qualitative case-study research. Nurse Res. 2013; 20 (4): 12-17. PMid:23520707 http://dx.doi.org/10.7748/nr2013.03.20.4.12.e326

[28] Taylor BJ, Kermode S, Roberts KL. Research in nursing and health care: evidence for practice, 4th ed. South Melbourne, Australia: Cengage Learning Australia Pty. Limited, 2011.

[29] Duffy, K. A grounded theory investigation of factors which influence the assessment of students' competence to practice. London, UK: Nursing and Midwifery Council, 2004.

[30] Teeter MM. Formula for success: addressing unsatisfactory clinical performance. Nurse Educ. 2005; 30(3): 91-2. PMid:15900193 http://dx.doi.org/10.1097/00006223-200505000-00002

[31] Walsh, CM, \& Seldomridge LA. Clinical grades: upward bound. J of Nurs Educ. 2005; 44(4): 162-168. PMid:15862049

[32] Lewallen LP, DeBrew JK. Successful and unsuccessful clinical nursing students. J Nurs Educ. 2012; 51(7): $389-395$. PMid:22533497 http://dx.doi.org/10.3928/01484834-20120427-01

[33] Tanicala ML, Scheffer BK, Roberts MS. Defining pass/fail nursing student clinical behaviors phase I: moving toward a culture of safety. Nurs Educ Persp. 2011; 32(3): 155-61. http://dx.doi.org/10.5480/1536-5026-32.3.155

[34] Duffy K, Hardicre J. Supporting students in practice 2: management. Nurs Times. 2007; 103(48): $28-9$.

[35] Luhanga F, Yonge O, Myrick F. Precepting an unsafe student: The role of faculty. Nurse Educ Today. 2008; 28(2): 227-31. PMid:17553601 http://dx.doi.org/10.1016/j.nedt.2007.04.001

[36] Gallant M, MacDonald JA, Smith KA. A remediation process for nursing students at risk for clinical failure. Nurse Educ. 2006; 31(5): 223-7. PMid:16980827 http://dx.doi.org/10.1097/00006223-200609000-00010

[37] Earle-Foley V, Myrick F, Luhanga F, Yonge O. Preceptorship: using an ethical lens to reflect on the unsafe student. J Prof Nurs. 2012; 28(1): 27-33. PMid:22261602 http://dx.doi.org/10.1016/j.profnurs.2011.06.005

[38] Hunt LA, McGhee P, Gutteridge R, Hughes M. Assessment of student nurses in practice. A comparison of theoretical and practical assessments in England. Nurse Educ Today. 2012; 32(4): 351-5. PMid:21640448 http://dx.doi.org/10.1016/j.nedt.2011.05.010 